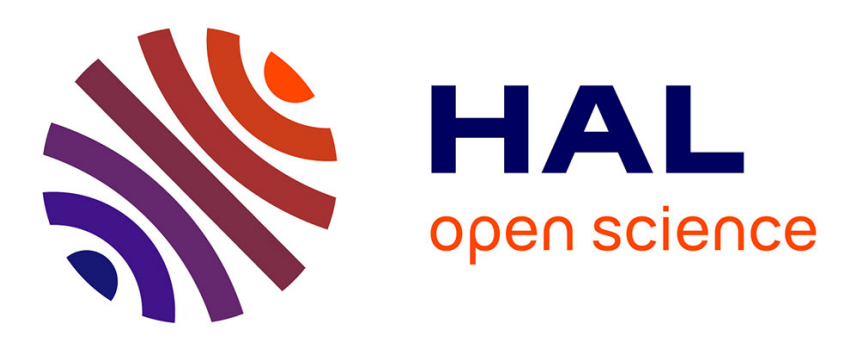

\title{
Magneto-Structural and Computational Study of a Tetranuclear Copper Complex Displaying Carbonyl- $\pi$ Interactions
}

Amélie Kochem, Bruno Faure, Sylvain Bertaina, Eric Riviere, Michel Giorgi, Marius Réglier, Maylis Orio, A. Jalila Simaan

\section{To cite this version:}

Amélie Kochem, Bruno Faure, Sylvain Bertaina, Eric Riviere, Michel Giorgi, et al.. MagnetoStructural and Computational Study of a Tetranuclear Copper Complex Displaying Carbonyl$\pi$ Interactions. European Journal of Inorganic Chemistry, 2018, 2018 (47), pp.5039-5046. 10.1002/ejic.201801032 . hal-02089367

\section{HAL Id: hal-02089367 https://hal.science/hal-02089367}

Submitted on 16 Dec 2021

HAL is a multi-disciplinary open access archive for the deposit and dissemination of scientific research documents, whether they are published or not. The documents may come from teaching and research institutions in France or abroad, or from public or private research centers.
L'archive ouverte pluridisciplinaire HAL, est destinée au dépôt et à la diffusion de documents scientifiques de niveau recherche, publiés ou non, émanant des établissements d'enseignement et de recherche français ou étrangers, des laboratoires publics ou privés. 
WILEY-VCH

1

2

\begin{abstract}
A tetranuclear copper(II) complex (1) was synthetized using 2-hydroxy-N-(quinolin-8-yl)acetamide ligand. Single-crystal X-ray diffraction studies revealed that the complex consists of a distorted $\mathrm{Cu}_{4} \mathrm{O}_{4}$ core in which the four copper(II) ions are linked by alkoxo bridges. X-ray analysis also evidenced intramolecular non-covalent carbonyl- $\pi$ interactions. Those interactions that are encountered between lone-pair electrons (of the amide oxygen atoms here) and $\pi^{*}$ orbitals of aromatic rings, have been recently recognized as important stabilizing interactions (named $n \rightarrow \pi^{*}{ }_{A r}$ ). Computational studies using density functional theory (DFT) were conducted to evaluate the structural role of such interactions in the present tetranuclear entity. The magnetic properties of $\mathbf{1}$ were also investigated and DFT calculations were employed to predict, rationalize and correlate the exchange interactions operating within this original complex.
\end{abstract}

\section{Introduction}

Polynuclear copper(II) complexes have attracted much attention in the past decades owing to their interesting potential applications in different fields such as bioinorganic chemistry as mimics for multicopper active sites of metalloproteins, ${ }^{[1]}$ coordination polymers, ${ }^{[2]}$ magnetochemistry ${ }^{[3]}$ and catalysis. ${ }^{[4]}$ Among polynuclear complexes, tetranuclear cubane-like $\mathrm{Cu}_{4} \mathrm{O}_{4}$ complexes containing oxygen bridges have received continuous attention and account for one of the most common arrangements of tetranuclear complexes (Scheme 1). ${ }^{[5]}$ While the extensive analysis of magneto-structural correlations of cubane-type tetranuclear complexes $\mathrm{Cu}_{4} \mathrm{O}_{4}$ complexes has allowed the understanding of the main structural factors that govern the magnetic exchange interaction in this type of systems, ${ }^{[6]}$ much less attention has been dedicated to tetranuclear copper(II) complexes that do not belong to this class of complexes. In addition, a special attention has been dedicated in the understanding of the driving forces that govern the self-assembly

[a] Dr. A Kochem, Dr. B. Faure, Dr. M. Réglier, Dr. M. Orio, Dr. A.J. Simaan

Aix Marseille Univ, CNRS, Centrale Marseille, iSm2, Marseille, France

E-mail: maylis.orio@univ-amu.fr; jalila.simaan@univ-amu.fr

[b] Dr. S. Bertaina

Aix Marseille Univ, CNRS, IM2NP, Marseille, France

[c] Dr. E. Rivière

Institut de Chimie Moléculaire et des Matériaux d'Orsay, Univ Paris Sud, Université Paris-Saclay, CNRS, Orsay, France

[d] Dr. M. Giorgi

Aix Marseille Univ, CNRS, Spectropole FR1739, Marseille, France

Supporting information for this article is given via a link at the end of the document of supramolecular structures. Non-covalent interactions have been shown to play a crucial role in this process. Among these interactions, the hydrogen bonding interactions ${ }^{[7]}$ are probably the most popular ones, followed by interactions involving $\pi$-systems such as $\pi$-stacking, $\pi$-hydrogen bonding and cation- $\pi$ interactions. ${ }^{[8]}$ In addition, $\mathrm{n} \rightarrow \pi^{*}$ interactions (also termed lonepair $\pi$ interactions) have recently emerged as important stabilizing interactions. ${ }^{[9,10,11]}$ These $n \rightarrow \pi^{*}$ interactions are found between an electron rich species and a $\pi$-electron cloud and have been classified into two types: $n \rightarrow \pi^{*}{ }_{A m}$ (amide) and $n \rightarrow \pi^{*}{ }_{A r}$ (aromatic). ${ }^{[12]}$ The $n \rightarrow \pi^{*}$ Am interactions have been described as interactions between electrons from a lone-pair orbital of a carbonyl oxygen donor with the antibonding $\pi^{*}$ orbital of a neighboring carbonyl group acceptor, thereby drawing the carbonyl groups closer. The $n \rightarrow \pi^{*}$ Ar interactions have been described as interactions between lone-pair electrons from a donor atom (e.g. oxygen, nitrogen) with the $\pi^{*}$ orbital of an aromatic ring. ${ }^{[11,13]}$ The importance of such $n \rightarrow \pi^{*}$ interactions has clearly been evidenced in biological systems. In addition, a growing number of examples involving small synthetic molecules have been reported in the literature, and their importance in the stabilization of molecular or supramolecular assemblies is possibly under-estimated..$^{[10,14,15]}$

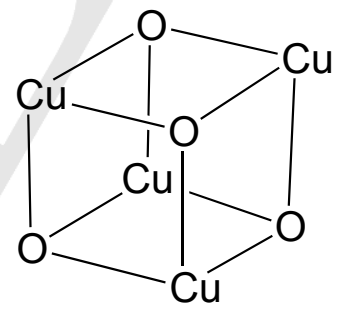<smiles></smiles>

Scheme 1. Representation of $\mathrm{Cu}_{4} \mathrm{O}_{4}$ cubane like complex (left) and representation of the core of 1 (right).

In this study, we report the synthesis and magneto-structural characterization of a tetranuclear copper(II) complex displaying an unusual $\mathrm{Cu}_{4} \mathrm{O}_{4}$ core. The ligand 2-hydroxy-N-(quinolin-8$\mathrm{yl}$ )acetamide $\left(\mathrm{H}_{2} \mathrm{~L}\right)$ was synthetized and the corresponding tetranuclear complex $\left[\left(\mathrm{Cu}_{4} \mathrm{~L}_{4}\right)\left(\mathrm{CH}_{3} \mathrm{OH}\right)_{2}\right] 3\left(\mathrm{H}_{2} \mathrm{O}\right)(1)$ was prepared (Scheme 2). Single-crystal $\mathrm{X}$-ray diffraction studies revealed that complex 1 consists of a "saddle-shaped" $\mathrm{Cu}_{4} \mathrm{O}_{4}$ core that doesn't belong to the well-known cubane-like family (Scheme 1). The four copper(II) ions are linked by alkoxo bridges and intermolecular hydrogens bonding interactions as well as intramolecular $n \rightarrow \pi^{*}$ interactions are detected. To the best of our knowledge, such $n$ $\rightarrow \pi^{*}$ interactions have not been identified and rationalized in copper complexes so far. Density functional theory (DFT) was used to provide a rational of the magnetic interactions within this 
complex as well as an estimate of the energy of intramolecular $n$ $\rightarrow \pi^{*}$ interactions.<smiles>O=C(CO)Nc1cccc2cccnc12</smiles>

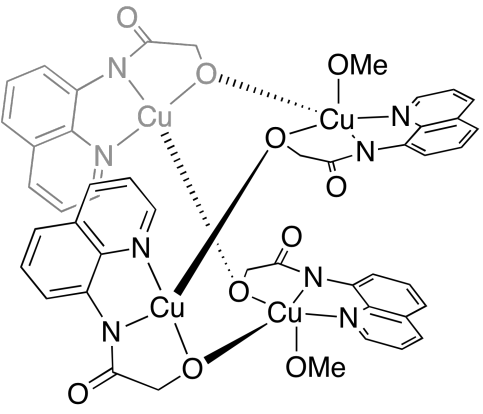

$\mathrm{H}_{2} \mathrm{~L}$

Scheme 2. Representation of the ligand $\mathrm{H}_{2} \mathrm{~L}$ and of complex 1 .

\section{Results and Discussion}

Synthesis and Structural Characterization. The ligand 2hydroxy-N-(quinolin-8-yl)acetamide, $\quad \mathbf{H}_{2} \mathbf{L}$ (Scheme 2), was obtained with high yield in one single-step by stoichiometric condensation of 8-aminoquinoline with glycolic acid. The tetranuclear complex $1\left(\left[\left(\mathrm{Cu}_{4} \mathrm{~L}_{4}\right)\left(\mathrm{CH}_{3} \mathrm{OH}\right)_{2}\right] 3\left(\mathrm{H}_{2} \mathrm{O}\right)\right)$ was obtained by mixing $\mathrm{H}_{2} \mathrm{~L}$ with 1 equivalent of copper(II) tetrafluoroborate and 2 equivalents of $\mathrm{Et}_{3} \mathrm{~N}$ in a mixture of methanol and acetonitrile. Green crystals were obtained by slow evaporation of the resulting solution stirred overnight, and the crystal structure was determined by single-crystal X-ray diffraction (Figures 1 and S1 in supporting information). Selected bond lengths, distances and angles are displayed in Figure 2.

Figure 1. Atomic displacement parameters plot (drawn at 30\% probability level) of 1 and partial atom labeling scheme. Hydrogen atoms and water molecules are omitted for clarity.

The tetranuclear complex 1 crystallizes in monoclinic space group $\mathrm{C} 2 / \mathrm{c}$ with two half-units related by symmetry through a crystallographic two-fold axis located at the center of the core unit.

This latter is composed of four alkoxo-bridged copper(II) ions forming a "saddle-shaped" structure. The four copper ions are coordinated in equatorial position by two oxygen atoms from the alkoxo bridges and two nitrogen atoms from the ligands. Two copper ions (Cu2 and its symmetric-related Cu2') are in a quite ideal square planar geometry ( $\tau$ parameter is equal to 0.06$)^{[16]}$ while Cu1 and its symmetric-related Cu1' are in a perfect square pyramidal geometry ( $\tau$ parameter is equal to 0.08 ) with one molecule of methanol weakly coordinated in axial position $(2.474$ $\AA$ for Cu1-O5 and Cu1'-O5'). The Cu-N and Cu-O distances in equatorial positions range from 1.895 to $2.009 \AA$ and from 1.899 to $1.943 \AA$, respectively. Analysis of the $\mathrm{Cu}-\mathrm{Cu}$ distances reveals four different bond lengths (3.4669(4) $\AA$ for Cu1-Cu1', 3.4004(7) $\AA$ for Cu1-Cu2 and Cu1'-Cu2', 3.3645(7) Å for Cu1-Cu2' and Cu2Cu1, and 3.1625(4) $\AA$ for Cu2-Cu2'). The structure was further examined in order to understand the forces that govern the $\mathrm{Cu}_{4} \mathrm{O}_{4}$ core distortion as well as the self-assembly of the molecules to form this tetranuclear structure.
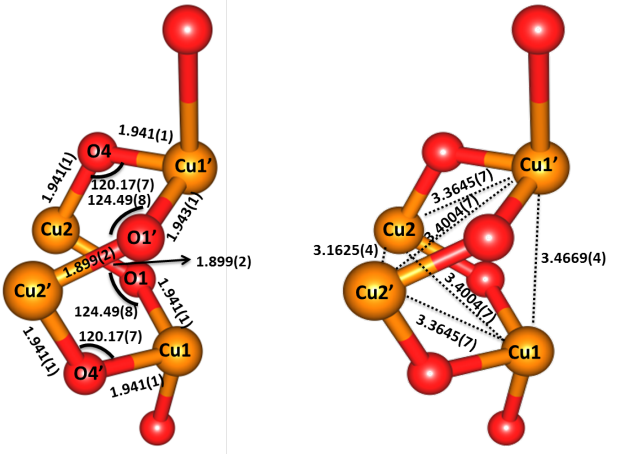

Figure 2. Side views of the $\mathrm{Cu}_{4} \mathrm{O}_{4}$ core of complex 1 and selected bond lengths, angles and distances.

When looking carefully at the structure, it appears that the $O$ atoms from two amide functions are located close to neighboring heteroaromatic quinoleine rings (Figure 3 ). This suggests the presence of intramolecular $n \rightarrow \pi^{*}{ }_{A r}$ interactions. In general, $C=O$ $\rightarrow \Pi^{*}$ Ar contacts are associated to the following distance and angle constraints: the distance $D$ between the carbonyl oxygen atom and the ring-centroid has to be between 2.8 and $3.8 \AA$, and the dihedral angle $\alpha$ between the planes defined by the amide backbone and the aromatic ring has to be smaller than $90^{\circ} .{ }^{[9]}$ In the present case, the distances (D) between the oxygen atoms O3 and O3' from the amide groups and the centers of the neighboring pyridine rings are of $3.49 \AA$ and the angle $\alpha$ of $86.25^{\circ}$ (Figure 3 ). This is in agreement with the geometrical constraints associated with amide lone-pair to $\pi^{*}{ }_{\mathrm{Ar}}$ interactions. This type of interaction might also exist between the oxygen atoms $\mathrm{O} 2$ and O2' and their neighboring pyridine rings although $\alpha$ values are in the upper limit $\left(d=3.49 \AA, \alpha=91.61^{\circ}\right)$. As mentioned previously, $n$ $\rightarrow \pi^{*}$ have been classified into two types: $n \rightarrow \pi^{*}$ Am (amide) and $\mathrm{n} \rightarrow \pi^{*}$ Ar (aromatic) ${ }^{[9,12]}$ The $\mathrm{n} \rightarrow \pi_{A m^{*}}{ }^{*}$ interactions have been found to be widely present in biomolecules and have been 
suggested to stabilize DNA and protein structures, ${ }^{[17,18,19,20,21]}$ and were predicted to engage $c a .45 \%$ of protein residues. ${ }^{[22]}$ The $n$ $\rightarrow \pi^{*}$ Ar interactions are also widely present in proteins and many examples have been found involving the backbone amide oxygen that is interacting with the side-chain of an aromatic residue..$^{[9,11]}$ Efforts have been dedicated towards the characterization of these $\mathrm{n} \rightarrow \pi^{*}$ interactions in materials and low-molecular weight molecules. ${ }^{[10,15]}$ Regarding intermolecular interactions, both oxygen $\mathrm{O} 3$ and $\mathrm{O}^{\prime}$ ' form a $\mathrm{C}=\mathrm{O} \ldots \mathrm{HOH}$ hydrogen bond with water molecules present in the crystal structure while $\mathrm{O} 2$ and $\mathrm{O} 2$ ' form a hydrogen bond with the coordinated methanol molecule from a neighboring tetranuclear complexes (Figure 3).
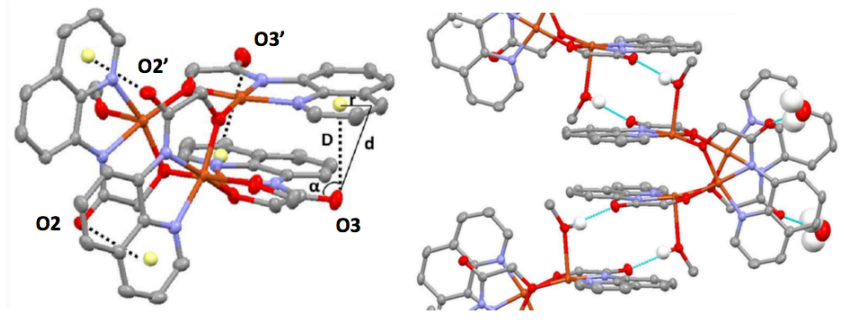

Figure 3. Atomic displacement parameters plot of non-covalent interactions and packing of $\mathbf{1}$. Hydrogen atoms except for those involved in $\mathrm{H}$-bonding interactions are omitted for clarity. The intramolecular $n \rightarrow \pi^{*}{ }_{A r}$ interactions are represented as black dashed lines between the oxygen atoms and the centroids of the aromatic rings (yellow balls) and the intermolecular $\mathrm{H}$-bonding interactions are represented as blue dashed lines.

Magnetic Properties. The magnetic behaviour of complex 1 was measured from 350 to $5 \mathrm{~K}$ (Figure 5 and S2). The value of the product $\left(X_{\mathrm{M}} \mathrm{T}\right)$ of the molar susceptibility $(X)$ and the temperature (T) is $0.847 \mathrm{~cm}^{3} \mathrm{~K} \mathrm{~mol}^{-1}$ at room temperature. This value is significantly lower than the one expected for four uncoupled $\mathrm{Cu}$ (II) ions $\left(1.5 \mathrm{~cm}^{3} \mathrm{~K} \mathrm{~mol}^{-1}\right.$ with $\left.\mathrm{g}=2\right)$ which indicates the existence of antiferromagnetic interactions between the $\mathrm{Cu}(\mathrm{II})$ ions mediated by the alkoxo bridges. As the temperature is lowered, the $X_{M} T$ product decreases continuously and $X_{\mathrm{M}}$ reaches a maximum at $220 \mathrm{~K}$ (Figure S2). This supports the predominance of antiferromagnetic interaction between the copper(II) ions. A multicenter magnetically coupled system is viewed as consisting of $N$ spin sites interacting through $N(N-1) / 2$ Heisenberg exchange couplings $J_{i j}$, and is described by the isotropic Heisenberg-Diracvan Vleck Hamiltonian (Equation 1, experimental section). ${ }^{[23]}$ In principle, six exchange pathways should be considered to describe the magnetic behavior of a tetranuclear transition metal complex. However, due to the C2 axial symmetry present in the structure of 1, the coupling scheme was simplified considering two main exchange interactions with $J_{12}=J_{1^{\prime} 2^{\prime}}=J_{1}$ and $J_{12^{\prime}}=J_{1^{\prime 2}}=J_{2}$. Two weak exchange interactions $\left(J_{11}\right.$, and $J_{22}$ ) are expected between the copper(II) ions that are not connected through alkoxide bridges and were thus neglected. By taking into account the above simplifications, the magnetic properties of complex 1 can be described using the following spin Hamiltonian (Equation 2):
$\mathcal{H}=-2 J_{1} \cdot\left(S_{\mathrm{Cu} 1} S_{\mathrm{Cu} 2}+S_{\mathrm{Cu} 1} S_{\mathrm{Cu}_{2}}\right)-2 J_{2} \cdot\left(S_{\mathrm{Cu} 1} S_{\mathrm{Cu} 2^{\prime}}+S_{\mathrm{Cu} 1} S_{\mathrm{Cu} 2}\right)($ Eq. 2$)$

The susceptibility data were fitted and two coupling constants of 116 and $-77 \mathrm{~cm}^{-1}$ were obtained from the best fit (with $\mathrm{g}=2.0, \mathrm{R}_{\mathrm{x}} \mathrm{T}$ $=1.410^{-4}$ and $R_{x}=1.910^{-4}$, see experimental section for details). Electron paramagnetic resonance (EPR) measurements were performed on complex 1 using a X-band spectrometer. A small signal was observed and was attributed to isolated copper ions. Indeed, the signal observed at $100 \mathrm{~K}$ is about twice larger than the one at $200 \mathrm{~K}$ suggesting a Curie behavior of a paramagnetic impurity. While the signal from 1 (if observed) is expected to decrease when the temperature decreases, the signal observed increases as expected for an isolated paramagnetic impurity (Figure S3).

Magneto-structural correlations have been established for $\mu$ alkoxo and $\mu$-hydroxo dinuclear copper complexes. Several studies on copper dimers have shown that a $\mathrm{Cu}-\mathrm{O}-\mathrm{Cu}$ angle $(\theta)$ greater than $98^{\circ}$ usually leads to an antiferromagnetic coupling while ferromagnetism appears for smaller values of $\theta .^{[24]}$ Therefore, the antiferromagnetic coupling observed between the four copper ions in $\mathbf{1}$ are likely due to the large $\mathrm{Cu}-\mathrm{O}-\mathrm{Cu}$ angles and the slightly greater Cu1-O-Cu2 and Cu1'-O-Cu2' angles $\left(124.49(8)^{\circ}\right)$ when compared to Cu1'-O-Cu2 and Cu1-O-Cu2' $\left(120.17(7)^{\circ}\right)$ could account for the significant differences in $J$ values. It is thus possible to determine $J_{1}=-116 \mathrm{~cm}^{-1}$ and $J_{2}=$ $77 \mathrm{~cm}^{-1}$ and this assignment is further supported by our DFT calculations (see next section). Moreover, antiferromagnetic interactions are known to be stronger when the electron density is increased on the corresponding bridging atoms. ${ }^{[25]}$ Therefore, the magnitude of the exchange coupling constants $J_{1}$ and $J_{2}$ is consistent with the presence of electron-enriched deprotonated 2hydroxy-N-(quinolin-8-yl)acetamido bridging ligands.

Computational studies: magnetic properties. In an effort to get further insight into the magnetic behavior of the present tetranuclear compound, density functional theory (DFT) calculations were conducted. Complex $\mathbf{1}$ consists of four magnetically interacting copper (II) centers and can be reasonably well described by the BS-DFT approach, ${ }^{[26]}$ as already demonstrated in studies of related systems. ${ }^{[27]}$ The predicted number of possible pairwise exchange couplings is six and can be determined within the BS-DFT framework. For that purpose, we first assumed that locally all spins on each metal center are aligned in parallel (local high-spin configurations). Then a separate solution for each of the possible spin configurations of the cluster is computed with either a positive or a negative sign of the local spin on each center. In the case of a tetranuclear complex, eight distinct spin configurations exist $\left(2^{n-1}\right)$ and the energies of these different spin configurations can be computed. Assuming a non-symmetrical structure, a $S=2$ high spin (HS) configuration, four $M_{S}=1 \mathrm{BS}$ solutions and three $M_{S}=0 \mathrm{BS}$ solutions can be thus generated (Figure 4 and Table S1). The energy of each spin configuration can be written as linear combination of the local spin of each magnetic center and the individual exchange coupling constant which results in a series of eight equations. 

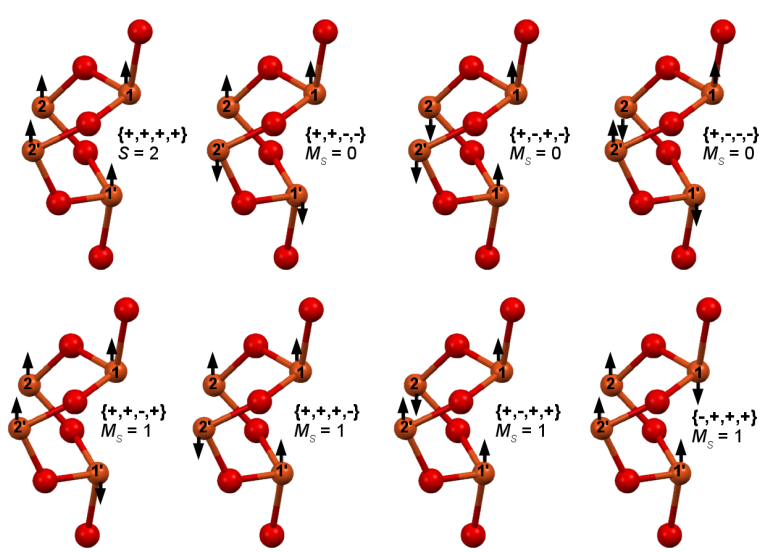

Figure 4. Representation of the spin configurations in $\mathbf{1 .}$

Since there are more equations than $J$ values, the system is overdetermined and the solution is, in principle, not unique. To deal with this situation we have solved the systems of linear equations via singular value decomposition (SVD). The SVD approach guarantees that the set of $J$ values is unique, representing the best possible solution in the least squares sense, i.e. the solution with the smallest residual norm. ${ }^{[28]}$ Using this methodology, the following $J$ values were extracted for 1: $J_{12}=-103 \mathrm{~cm}^{-1}, J_{1^{\prime} 2^{\prime}}=-99$ $\mathrm{cm}^{-1}, J_{12^{\prime}}=-75 \mathrm{~cm}^{-1}, J_{1^{\prime} 2}=-79 \mathrm{~cm}^{-1}, J_{11^{\prime}}=-4 \mathrm{~cm}^{-1}, J_{22^{\prime}}=-6 \mathrm{~cm}^{-1}$. The calculated $J$-values based on the BS-DFT approach compared to the experimentally-derived values are collected in Table 1, together with the relevant energy spectrum calculated by a direct diagonalization of the Heisenberg-Dirac-Van Vleck (HDvV) Hamiltonian. ${ }^{[23]}$ The total spin of the ground and the lowest excited states, as well as the energetic separation between the ground and the lowest spin multiplets are reported in Table 1.

Table 1. Experimental and calculated exchange coupling constants $J\left(\mathrm{~cm}^{-1}\right)$ and lowest energy levels $\left(\mathrm{cm}^{-1}\right)$ for the different higher $\mathrm{S}$-states of the $\mathrm{Cu}_{4} \mathrm{O}_{4}$ species relative to the $S=0$ Ground State.

\begin{tabular}{|c|c|c|}
\hline & Exp. & Calc. \\
\hline$J_{12}$ & -116 & -103 \\
\hline$J_{1^{\prime} 2^{\prime}}$ & -116 & -99 \\
\hline$J_{12}$ & -77 & -75 \\
\hline$J_{1^{\prime 2}}$ & -77 & -79 \\
\hline$J_{11}$ & 0 & -4 \\
\hline$J_{22^{\prime}}$ & 0 & -6 \\
\hline$S=2$ & 590 & 539 \\
\hline$S=1$ & 436 & 376 \\
\hline$S=0$ & 409 & 348 \\
\hline$S=1$ & 358 & 328 \\
\hline$S=1$ & 204 & 183 \\
\hline$S=0$ & 0 & 0 \\
\hline
\end{tabular}

Our calculations resulted in three pairs of similar $J$ values due to the slightly asymmetric structure resulting from the DFTconstrained optimization of 1 . The sign and the relative magnitude of the computed exchange coupling constants are in good agreement with the experimental results and confirm the antiferromagnetic interaction between the copper centers. The computed magnetic sublevel spectrum indeed supports that the ground spin state is a singlet state while the first excited spin state is a triplet state and that their energetic separation closely matches the value probed by experiment. The same observation can be also made for the next excited states which feature similar energies and spin states when comparing experimental and computed data.

Interestingly, the computed exchange coupling constants also confirm the magneto-structural correlations. ${ }^{[24]}$ The magnitude of $J_{12}$ and $J_{1}{ }^{\prime 2}$, is much greater than that of $J_{12}$, and $J_{1 ' 2}$ consistent with the fact that the Cu1OCu2 and Cu1'OCu2' angles are larger than Cu1'OCu2 and Cu1OCu2' angles in both the crystal and optimized structure of $\mathbf{1}$. It is also worth noting that very weak antiferromagnetic interactions were predicted for the copper centers that do not exhibit any bridging fragment $\left(J_{11}=-4 \mathrm{~cm}^{-1}\right.$ and $J_{22^{\prime}}=-6 \mathrm{~cm}^{-1}$ ). These qualitative observations are in line with the DFT-calculated electronic structure of $\mathbf{1}$ in its high spin state (see Figure S4). All four Singly Occupied Molecular Orbitals (SOMOs) feature a dominant $\mathrm{Cu} 3 \mathrm{~d}_{\mathrm{x} 2-\mathrm{y} 2}$ character and are mainly localized in the basal plane of the metal centers. They have significant contributions of the coordinating atoms especially the bridging oxygen atoms which will lead to significant overlap between these orbitals and result in strong magnetic interactions between the metal centers. In addition to the above analysis we have also reconstructed the magnetic susceptibility curve $\left(\chi_{\mathrm{M}} . T\right.$ vs $T$ ) using the computed exchange coupling constants. The resulting curve is presented in Figure 5 together with the experimental data emphasizing the nice correlation between theory and experiment.

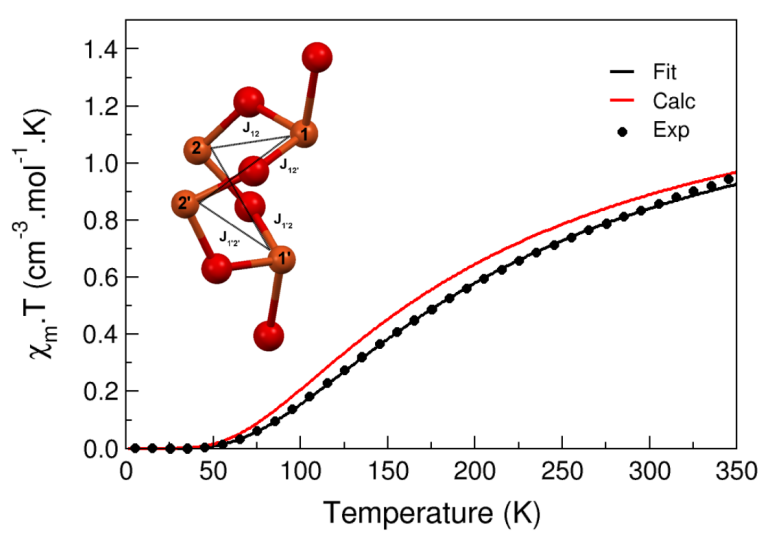

Figure 5. Plot of the $\chi_{M} T$ product per mole of 1 vs temperature. The solid black line corresponds to the best fit of the experimental data (black circle) with $\mathrm{g}=$ 2.029 (fixed value), $J_{1}=-116 \mathrm{~cm}^{-1}, J_{2}=-77 \mathrm{~cm}^{-1}$. The solid red line has been calculated using the theoretical values of $J_{12}=-103 \mathrm{~cm}^{-1}, J_{1{ }^{\prime} 2^{\prime}}=-99 \mathrm{~cm}^{-1}, J_{12}=$ $-75 \mathrm{~cm}^{-1}, J_{1^{\prime} 2}=-79 \mathrm{~cm}^{-1}, J_{11^{\prime}}=-4 \mathrm{~cm}^{-1}, J_{22^{\prime}}=-6 \mathrm{~cm}^{-1}$. Inset: schematic view of complex 1 with the relevant magnetic exchange interactions between the four copper centers. 
Computational studies: non-covalent interactions. Based on the analysis of the crystal structure, several $n \rightarrow \pi^{*}$ Ar interactions were evidenced, which may contribute to the stabilization of the tetranuclear core of 1 . Recently, we have reported on the major role of intramolecular copper- $\pi$ interactions in the core stabilization of a tetranuclear copper(II) cubane complex. ${ }^{[29]}$ DFT calculations were thus performed in order to quantify the energy of the $n \rightarrow \pi^{*}$ Ar interactions. Calculations were conducted by using the range-separated wB97X-D3 functional and the structure resulting from DFT-constrained optimization of 1 . In order to model the interactions involving the oxygen atoms and their neighboring pyridine rings we have used a fragment-based approach.

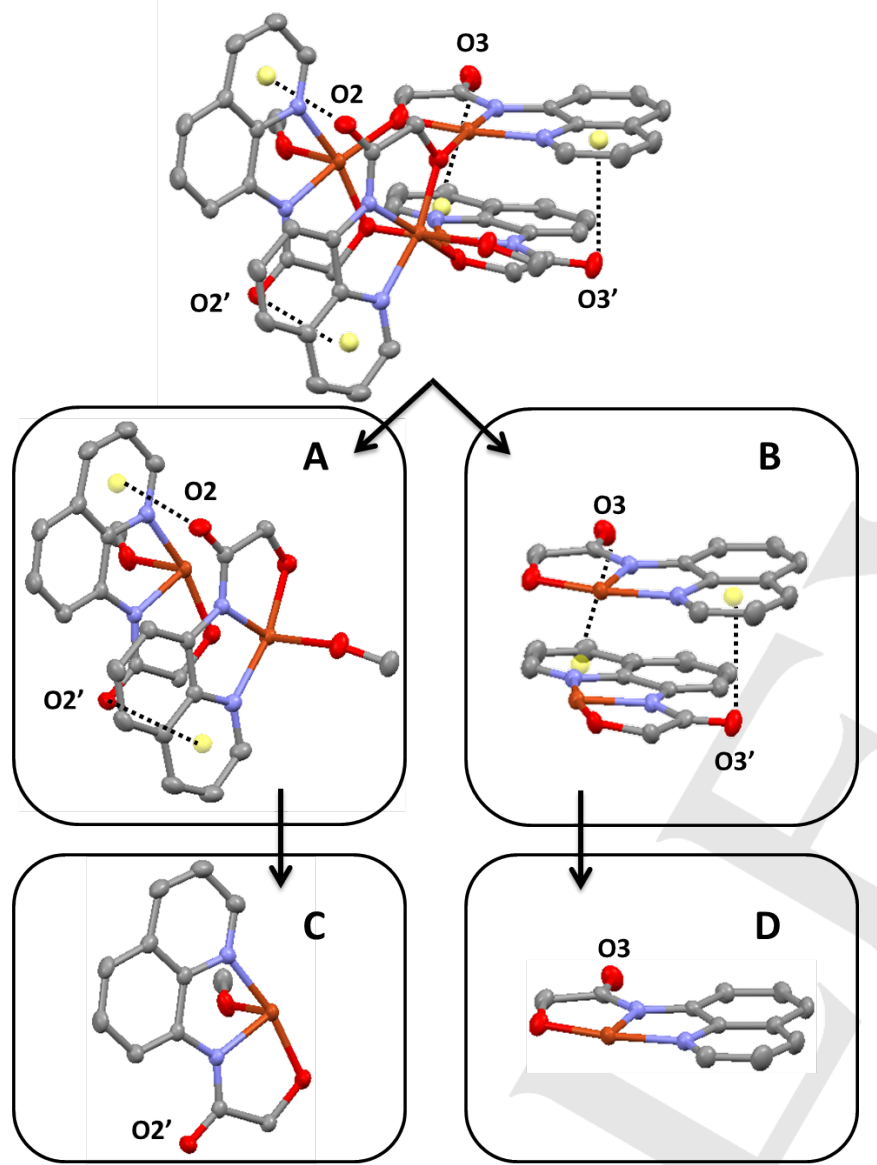

Figure 6 Fragments considered for the DFT-modeling of the $n \rightarrow \pi^{*}{ }_{\text {Ar }}$ in 1 .

Four distinct fragments, namely $A, B, C$ and $D$, were considered as shown in Figure 5. Fragment $A$ consists of one half of the tetranuclear unit and includes oxygen atoms $\mathrm{O} 2$ and $\mathrm{O} 2$ ' while fragment $B$ is composed of the second half of the tetranuclear unit and incorporates oxygen atoms $\mathrm{O} 3$ and $\mathrm{O} 3$ '. Fragment $\mathrm{C}$ consists of one quarter of the tetranuclear unit and includes the ligand $L$ and the methanol molecule coordinated to the copper ion Cu1 while fragment $D$ is composed of the ligand $L$ coordinated to the copper ion Cu2. The $n \rightarrow \pi^{*}$ Ar interaction between the oxygen atoms $\mathrm{O} 2$ and $\mathrm{O} 2$ ' and the heteroaromatic quinoleine rings as well as those involving involving oxygen atoms $\mathrm{O} 3$ and $\mathrm{O}^{\prime}$ ' can be evaluated using the following energetic analysis:

$\mathrm{E}\left(\mathrm{n} \rightarrow \pi^{*}{ }_{\mathrm{Ar}}\right)=\mathrm{E}_{1}+\mathrm{E}_{2}$

$E_{1}=E(A)-2 \times E(C)$ and $E_{2}=E(B)-2 \times E(D)$

Where $E(A), E(B), E(C)$ and $E(D)$ are the Gibbs free energies of fragments $A, B, C$ and $D$, respectively.

Using this approach, values of $1.3 \mathrm{kcal}^{\mathrm{mol}}{ }^{-1}$ and $1.8 \mathrm{kcal} . \mathrm{mol}^{-1}$ were obtained for the interaction energies $E_{1}$ and $E_{2}$, respectively. In the literature, theoretical studies have been applied to simple model systems in order to evaluate the energies of various $n \rightarrow$ $\pi^{*}$ interactions. ${ }^{[9]}$ For instance, the energy of carbonyl-carbonyl $n$ $\rightarrow \pi^{*}$ Am interactions has been estimated at $0.27-0.7 \mathrm{kcal}^{\mathrm{mol}}{ }^{-1}{ }^{[21]}$ Lone pair $-\pi$ interactions between water oxygens and aromatic residues were calculated ranging from 0.1 to $5 \mathrm{kcal} / \mathrm{mol} .{ }^{[20]}$ Our calculated values are therefore in line with $n \rightarrow \pi^{*}$ interaction energies that were calculated in model systems and account for ca. $3.1 \mathrm{kcal}^{\mathrm{mol}} \mathrm{l}^{-1}$ of the energy of the unusual saddle-shaped structure of 1 . A more detailed analysis of these non-covalent interactions has been obtained from additional theoretical calculations conducted within the Natural Bond Orbital (NBO) framework, a technique that can directly observe bonding and electron density between specific centres in a molecule. The explicit examination of the $n \rightarrow \pi^{*}{ }_{A r}$ interactions within the complex was undertaken using the second-order perturbative analysis which estimates the donor-acceptor interactions in the NBO basis. For each donor NBO (i) and acceptor NBO (j), the two-electron stabilization energy associated with delocalization is estimated as follows:

$$
\Delta E_{i j}=q_{i} \frac{F(i, j)^{2}}{\varepsilon_{i}-\varepsilon_{j}}
$$

Where $q_{i}$ is the donor orbital occupancy, $\varepsilon_{i}, \varepsilon_{j}$ are diagonal elements (orbital energies) and $F(i, j)$ is the off-diagonal NBO Fock matrix element. The results of the NBO calculations are presented in Table 3 and the atom labelling is displayed in Figure S5.

Table 2. Stabilization energies $\left(\mathrm{kcal} \cdot \mathrm{mol}^{-1}\right)$ from Natural Bond Orbital analysis

\begin{tabular}{ccc}
\hline Donor NBO (i) & Acceptor NBO (ii) & Stabilization energy, $\Delta E_{i j}$ \\
\hline $\mathrm{O}_{2}$ & $\mathrm{~N}_{62}-\mathrm{C}_{77}$ & 0.9 \\
$\mathrm{O}_{2}{ }^{\prime}$ & $\mathrm{N}_{8}-\mathrm{C}_{23}$ & 0.9 \\
$\mathrm{O}_{3}$ & $\mathrm{~N}_{64}-\mathrm{C}_{96}$ & 1.6 \\
$\mathrm{O}_{3}{ }^{\prime}$ & $\mathrm{N}_{10}-\mathrm{C}_{42}$ & 1.6
\end{tabular}

The data collected from NBO analysis shows several stabilizing interactions of similar energy and origin as they are due to the oxygen donation from the amide group lone pairs to the antibonding orbitals involving the pyridine rings. These results thus support the importance of the non-covalent $n \rightarrow \pi^{*} \mathrm{Ar}$ interactions that probably act as one of the driving forces for the aggregation process. 


\section{Conclusions}

In summary, we have obtained a new example of a tetranuclear copper complex, which consists of a distorted $\mathrm{Cu}_{4} \mathrm{O}_{4}$ core with four $\mathrm{Cu}(\mathrm{II})$ ions linked by alkoxo bridges. The X-ray structure has been resolved and showed a non-common saddle-shaped core as many tetranuclear copper clusters usually build cubane-like entities. The electronic structure and the magnetic properties were investigated through a combination of experimental techniques and quantum chemistry. Looking at the magnetic properties, the quantum chemical analysis of the tetranuclear unit provides an excellent match with the experimental data that can be also rationalized using magneto-structural correlations. The solid state structural data suggested the presence of intramolecular $n \rightarrow \pi^{*}$ Ar interactions between the amide groups and the aromatic rings possibly contributing to the stabilization of this unusual distorted $\mathrm{Cu}_{4} \mathrm{O}_{4}$ core and to the aggregation process. The presence and the energy of such interaction was supported by DFT calculations. Further work is in progress in our laboratory to prepare a series of copper analogues to elucidate the exact role of these $n \rightarrow \pi^{*}$ interactions and their possible influence on the magnetic behaviour of the resulting copper complexes. Finally, the behaviour of the present system in solution (magnetic, redox and catalytic properties) has yet to be explored. Indeed, noninnocent ligands being present, they can be used to turn this complex into a metal-radical assembly making a potential candidate as a novel redox-switchable metallo-organic supramolecular assembly.

\section{Experimental Section}

General. The solvents used for chemical reactions, electrochemistry and spectroscopic characterization were purified by the solvent purification system innovative technology PS-MD-5. Microanalysis was performed on an Elementar Thermo Finnigan EA 1112. NMR-spectra were recorded at room temperature using a Brucker-Avance III nanobay spectrometer operating at 300 or $400 \mathrm{MHz}$ for ${ }^{1} \mathrm{H}$. Chemical shifts are given relative to residual peaks of solvent (listed in ppm). Data are presented as follows: chemical shift (in ppm on the $\delta$ scale relative to $\delta_{\mathrm{CHCl} 3}=7.26$ ), multiplicity ( $\mathrm{s}=$ singlet, $\mathrm{d}=$ doublet, $\mathrm{t}=$ triplet, $\mathrm{q}=$ quartet, quint. = quintuplet, sext. = sextuplet, sept. = septuplet, $\mathrm{m}=$ multiplet, br. = broad, app. = apparent), coupling constant $(\mathrm{J} / \mathrm{Hz})$ and integration. ESI-MS analyses were performed using a SYNAPT G2 HDMS (Waters) spectrometer equipped with a pneumatically assisted Atmospheric Pressure lonization (API) source. Samples were ionized by positive electrospray mode as follows: ion-spray voltage: $2.8 \mathrm{kV}$; orifice lens: $60 \mathrm{~V}$ and $40 \mathrm{~V}$ for $\mathbf{H}_{\mathbf{2}} \mathrm{L}$ and 1 respectively; nitrogen flux (nebulization): $100 \mathrm{~L} . \mathrm{h}^{-1}$. High resolution mass spectra (HRMS) were performed on a QStar Elite (Applied Biosystems SCIEX) spectrometer equipped with atmospheric pression ionization source (API) pneumaticly assisted. Samples of $\mathbf{H}_{2} \mathrm{~L}$ and 1 were placed in a methanol / $3 \mathrm{mM}$ ammonium acetate. The results were validated by three measurements. X-Band EPR measurements were carried out at $9.6 \mathrm{GHz}$ with a BRUKER EMX9/2.7 spectrom- eter equipped with a B-VT2000 digital temperature controller $(100-400 \mathrm{~K})$.

Synthesis of $\mathrm{H}_{2} \mathrm{~L}$ : Glycolic acid $(0.53 \mathrm{~g}, 6.9 \mathrm{mmol})$ was added to a solution of 8 -aminoquinoline $(1.0 \mathrm{~g}, 6.9 \mathrm{mmol})$ dissolved in $20 \mathrm{~mL}$ toluene. The resulting solution was stirred under reflux overnight using a Dean-Stark apparatus. The solution was cooled down, filtered over a plug of celite, and the solvent was removed to give the desired product as a brownish powder (1.13 g, 80\% yield). ${ }^{1} \mathrm{H}$ NMR (300 MHz; $\left.\mathrm{CDCl}_{3}\right) 10.47$ (br, s, $\left.1 \mathrm{H}\right), 8.89$ (d, $\mathrm{J}=4.20 \mathrm{~Hz}, 1 \mathrm{H}), 8.78(\mathrm{t}, \mathrm{J}=4.20 \mathrm{~Hz}, 1 \mathrm{H}), 8.27(\mathrm{~d}, \mathrm{~J}=8.21 \mathrm{~Hz}, 1 \mathrm{H}), 7.61$ (d, J = $4.55 \mathrm{~Hz}, 1 \mathrm{H}), 7.54$ (dd, J = 4.37 Hz and $8.25 \mathrm{~Hz}, 2 \mathrm{H}), 4.44$ (s, 2H). HRMS ESI: $[\mathrm{M}+\mathrm{Na}]^{+}$calcd for $\mathrm{C}_{11} \mathrm{H}_{10} \mathrm{~N}_{2} \mathrm{O}_{2} \mathrm{Na}^{+}: 225.0634$, observed: 225.0634. Anal. Calc. for $\mathrm{C}_{11} \mathrm{H}_{10} \mathrm{~N}_{2} \mathrm{O}_{2}$ : C, 65.35; $\mathrm{H}, 4.98 ; \mathrm{N}, 13.85$. Found: C, $65.30 ; \mathrm{H}, 4.73 ; \mathrm{N}, 13.94$.

Synthesis of $\left[\left(\mathrm{Cu}_{4} \mathrm{~L}_{4}\right)\left(\mathrm{CH}_{3} \mathrm{OH}\right)_{2}\right] \cdot 3\left(\mathrm{H}_{2} \mathrm{O}\right)(1) . \mathrm{Cu}\left(\mathrm{BF}_{4}\right)_{2}(0.25 \mathrm{~g}, 1.05 \mathrm{mmol})$ dissolved in $5 \mathrm{~mL} \mathrm{MeOH}$ and $\mathrm{Et}_{3} \mathrm{~N}(0.29 \mathrm{~mL}, 2.11 \mathrm{mmol})$ were added sequentially to a solution of $\mathbf{H}_{2} \mathrm{~L}(0.21 \mathrm{~g}, 1.05 \mathrm{mmol})$ dissolved in acetonitrile $(7 \mathrm{~mL})$. The solution turned to dark green and was stirred at room temperature overnight. The complex was crystallized by slow evaporation of the solution. The crystals were collected and washed successively with ethanol $(10 \mathrm{~mL})$ and diethyl ether $(20 \mathrm{~mL})$. The product was isolated with 3 water molecules per complex. Yield: $0.134 \mathrm{~g}(44 \%)$. HRMS ESI: $[\mathrm{M}+\mathrm{H}]^{+}$calcd for $\mathrm{C}_{44} \mathrm{H}_{33} \mathrm{~N}_{8} \mathrm{O}_{8} \mathrm{Cu}_{4}{ }^{+}$: 1052.9600 , observed: 1052.9606. Anal. Calc. for $\mathrm{C}_{46} \mathrm{H}_{44} \mathrm{Cu}_{4} \mathrm{~N}_{8} \mathrm{O}_{13}$ : C, 47.18; $\mathrm{H}, 3.79 ; \mathrm{N}, 9.57$. Found: C, 47.18; H, 3.16; N, 9.89.

Single-Crystal $\mathrm{X}$-ray Diffraction data collection and refinement. Single crystals of $1\left(\mathrm{C}_{23} \mathrm{H}_{20.5} \mathrm{Cu}_{2} \mathrm{~N}_{4} \mathrm{O}_{5.25}\right)$ were grown by slow evaporation of a concentrated $\mathrm{CH}_{2} \mathrm{Cl}_{2} / \mathrm{EtOH}(1 / 1)$ solution of the compound. A suitable crystal was selected and mounted on a Rigaku Oxford Diffraction SuperNova diffractometer using CuK $\alpha$ radiation $(\lambda=1.54184 \AA)$. The crystal was kept at $173.00(10) \mathrm{K}$ during data collection. Data collection, cell refinement and data reduction were performed with CrysAlisPro (Rigaku Oxford Diffraction). Using Olex $2,{ }^{[30]}$ the structure was solved with the ShelXT ${ }^{[31]}$ structure solution program using Direct Methods and refined with the ShelX ${ }^{\left[{ }^{[32]}\right.}$ refinement package using Least Squares minimization. The hydrogen atoms were all found experimentally, except for the partial water molecule were they were introduced manually, and they were refined as riding atoms with their $\mathrm{U}_{\text {iso }}$ parameters fixed to $1.2 \mathrm{Ueq}$ (parent atom) for the aromatics and $\mathrm{CH}_{2}$ groups and to $1.5 \mathrm{Ueq}$ (parent atom) for the methyls, $\mathrm{OH}$ and water groups.

Table 3. Crystal data and structure refinement for complex 1.

\begin{tabular}{|c|c|}
\hline $\begin{array}{l}\text { Empirical formula } \\
\text { Formula weight }\end{array}$ & $\begin{array}{l}\mathrm{C}_{23} \mathrm{H}_{20.5} \mathrm{Cu}_{2} \mathrm{~N}_{4} \mathrm{O}_{5.25} \\
564.01\end{array}$ \\
\hline Temperature/K & $173.00(10)$ \\
\hline Crystal system & monoclinic \\
\hline Space group & $\mathrm{C} 2 / \mathrm{c}$ \\
\hline $\mathrm{a} / \AA \AA \AA$ & $10.20179(17)$ \\
\hline b/Å & $29.3679(4)$ \\
\hline $\mathrm{c} / \AA \AA$ & $14.8019(2)$ \\
\hline$\beta /^{\circ}$ & $110.0751(19)$ \\
\hline Volume $/ \AA^{3}$ & $4165.27(12)$ \\
\hline z & 8 \\
\hline$\rho_{\text {calc }} \mathrm{g} / \mathrm{cm}^{3}$ & 1.799 \\
\hline$\mu / \mathrm{mm}^{-1}$ & 2.940 \\
\hline$F(000)$ & 2292.0 \\
\hline Crystal size $/ \mathrm{mm}^{3}$ & $0.18 \times 0.04 \times 0.04$ \\
\hline Radiation & $\operatorname{CuK} \alpha(\lambda=1.54184)$ \\
\hline $2 \Theta$ range for data collection ${ }^{\circ}$ & 8.76 to 137.618 \\
\hline Index ranges & $-12 \leq h \leq 11,-35 \leq k \leq 34,-9 \leq 1 \leq 17$ \\
\hline Reflections collected & 15646 \\
\hline Independent reflections & $3834\left[R_{\text {int }}=0.0213, R_{\text {sigma }}=0.0171\right]$ \\
\hline Data/restraints/parameters & $3834 / 0 / 314$ \\
\hline Goodness-of-fit on $\mathrm{F}^{2}$ & 1.053 \\
\hline Final $R$ indexes $[l>=2 \sigma(I)]$ & $R_{1}=0.0265, w_{2}=0.0751$ \\
\hline Final $R$ indexes [all data] & $R_{1}=0.0284, w R_{2}=0.0764$ \\
\hline Largest diff. peak/hole / e $\AA^{-3}$ & $0.33 /-0.62$ \\
\hline
\end{tabular}


Magnetic Measurements. Magnetic susceptibility data were recorded on a Quantum Design SQUID Magnetometer with an applied field of $1000 \mathrm{G}$ The independence of the susceptibility value with regard to the applied field was checked at room temperature. Powder sample was measured in a gelatin capsule. The susceptibility data were corrected for the sample holder and the diamagnetic contributions as calculated from tables of Pascal's constants.

$\mathrm{R}_{\chi \mathrm{T}}=\left[\Sigma\left(\chi_{M} T_{\text {calc }}-\chi_{M} T_{\text {obs }}\right)^{2} / \Sigma\left(\chi_{M} T_{\text {obs }}\right)^{2}\right]$ and $\mathrm{P}_{\chi}=\left[\Sigma\left(\chi_{\text {Mcal }}-\chi_{\text {Mobs }}\right)^{2} / \Sigma\left(\chi_{\text {Mobs }}\right)^{2}\right]$

Computational Methods. All theoretical calculations were based on density functional theory (DFT) and have been performed with the ORCA program package. ${ }^{[33]}$ To facilitate comparisons between theory and experiment, we optimized the X-ray structure of the complex while constraining the positions of all heavy atoms to their experimentally derived coordinates. Thus, only the positions of the hydrogen atoms were relaxed since these are not reliably determined from X-ray diffraction. Geometry optimization was performed for the high-spin (HS) state with the GGA functional BP86 ${ }^{[34]}$ using the TZVP ${ }^{[35]}$ basis set for all atoms and by taking advantage of the resolution of the identity (RI) approximation in the Split-RI-J variant ${ }^{[36]}$ with the appropriate Coulomb fitting sets. ${ }^{\left[{ }^{[3]}\right.}$ Increased integration grids (Grid4 in ORCA convention) and tight SCF convergence criteria were used. Single-point Broken-Symmetry ${ }^{[26]}$ DFT calculations were performed with the hybrid functional B3LYP. ${ }^{[38]}$ All alternative spin configurations for the broken-symmetry calculations were generated with the "FlipSpin" feature of ORCA. The magnetic susceptibility curves were then reconstructed using the Easyspin program ${ }^{[39]}$ and the isotropic Heisenberg-Dirac-Van Vleck (HDvV) exchange Hamiltonian: ${ }^{[23]}$

$\mathcal{H}=-2 \sum_{i<j} J_{i j} S_{i} S_{j}$

Where $J_{i j}$ is the exchange coupling between pairwise number $i$ and $j$ while $S_{i}$ is the spin operator of the $i^{\text {th }}$ metal centre. The diagonalization of the HDVV Hamiltonian leads to the magnetic sublevel spectrum of the tetranuclear species which is composed of 16 states: 2 singlets, 3 triplets and 1 quintet of energy $E_{S 1}, E_{S 2}, E_{T 1}, E_{T 2}, E_{T 3}, E_{Q}$, respectively. This step was performed by employing the orca_eca utility of ORCA on both the experimental and theoretical data. The susceptibility derived from the Van Vleck equation is given by Equation $3:{ }^{[40]}$

$$
\begin{aligned}
& \chi T=\frac{N g^{2} \mu_{B}^{2}}{k} \frac{A}{B} \\
& A= 10 \exp \left(-E_{Q} / k T\right) \\
&+2\left(\exp \left(-E_{T 1} / k T\right)+\exp \left(-E_{T 2} / k T\right)+\exp \left(-E_{T 3} / k T\right)\right) \\
& B= 5 \exp \left(-E_{Q} / k T\right)+\exp \left(-E_{S 1} / k T\right)+\exp \left(-E_{S 2} / k T\right) \\
&+3\left(\exp \left(-E_{T 1} / k T\right)+\exp \left(-E_{T 2} / k T\right)+\exp \left(-E_{T 3} / k T\right)\right)
\end{aligned}
$$

Where $N$ is the Avogadro number, $g$ the $g$-factor, $\mu B$ the Bohr magneton and $k$ the Boltzman's constant.

Using the final energy levels $E_{S 1}, E_{S 2}, E_{T 1}, E_{T 2}, E_{T 3}, E_{Q}$ together with Eq. 2, one finally obtains the theoretical susceptibility curves presented in Figure 5 . The relative energies were obtained from single-point calculations using the $\omega B$ B $7 X-D 3^{[41]}$ functional together with the TZV/P basis set. They were computed from the gas-phase optimized structures as a sum of electronic energy and thermal corrections to free energy. Zero point vibrational energy (ZPVE) corrections $^{[42]}$ were evaluated from the calculated harmonic frequencies and are included in the total energies. The counterpoise $(\mathrm{CP})$ procedure was used to correct the total energy for the basis set superposition error (BSSE) ${ }^{[43]}$ Natural Bond Order (NBO) analyses ${ }^{[44]}$ were performed using the same functional ${ }^{[41]} /$ basis set $^{[35]}$ combination as employed before. Molecular orbitals were generated using the orca plot utility program and were visualized with the Chemcraft program. ${ }^{[45]}$

\section{Acknowledgements}

The authors acknowledge the French Research Agency (COMEBAC / ANR-13-BSO7-0018) for financial support and the COST action CM1305 ECOSTBio (Explicit Control Over SpinStates in Technology and Biochemistry) for scientific discussions.

Keywords: Copper $\cdot$ Magnetic properties $\cdot$ non-covalent interactions $\bullet$ lone pair $\pi$ interactions $\cdot$ DFT calculations

[1] a) E. I. Solomon, D. E. Heppner, E. M. Johnston, J. W. Ginsbach, J. Cirera, M. Qayyum, M. T. Kieber-Emmons, C. H. Kjaergaard, R. G. Hadt, L. Tian, Chem. Rev. 2014, 114, 3659-3853; b) G. Henkel, B. Krebs, Chem. Rev. 2004, 104, 801-824; c) P. Gamez, P. G. Aubel, W. L. Driessen, J. Reedijk, Chem. Soc.Rev. 2001, 30, 376-385; d)) E. I. Solomon, R. K. Szilagyi, S. DeBeer George, L. Basumallick, Chem. Rev. 2004, 104, 419-458

[2] a) A. Y. Robin, K. M. Fromm, Coord. Chem. Rev. 2006, 250, 2127-2157; b) S. Leininger, B. Olenyuk, P. J. Stang, Chem. Rev. 2000, 100, 853907; c) J. Y. Lu, Coord. Chem. Rev. 2003, 246, 327-347; d) A. Escuer, G. Vlahopoulou, S. P. Perlepes, M. Font-Bardia, T. Calvet Dalton Trans. 2011, 40, 225-233; e) N. R. de Campos, M. A. Ribeiro, W. X. Oliveira, D. O. Reis, H. O. Stumpf, A. C. Doriguetto, F. C. Machado, C. B. Pinheiro, F. Lloret, M. Julve, J. Cano, M. V. Marinho, Dalton Trans. 2016, 45, 172189; f) S. S. Tandon, S. D. Bunge, D. Motry, J. S. Costa, G. Aromí, J. Reedijk, L. K. Thompson, Inorg Chem. 2009, 48, 4873-4881

[3] a) G. Aromí, E. K. Brechin, Struct. Bonding, 2006, 122, 1-68; b) T. Mallah, A. Marvilliers, in Magnetism: Molecules to Materials I; Wiley-VCH Verlag GmbH \& Co.: Weinheim, Germany, 2001; pp 189-226; c) D. Gatteschi, R. J. Sessoli, Magn. Magn. Mater. 2004, 1030, 272-276

[4] a) M. M. Dıaz-Requejo, P. J. Pérez, Chem. Rev. 2008, 108, 3379-3394; b) A. M. Kirillov, M. V. Kirillova, A. J. L. Pombeiro, Coord. Chem. Rev. 2012, 256, 2741-2759

[5] a) G. A. Ardizzoia, S. Brenna, Coord. Chem. Rev., 2016, 311, 53-74; b) P. Seppälä, R. Sillanpää, A. Lehtonen, Coord. Chem. Rev. 2017, 347, 98-114

[6] a) R. Mergehenn, W. Haase, Acta Crystallogr., Sect. B 1977, 33, 18771882; b) E. Ruiz, S. Alvarez, A. Rodríguez-Fortea, P. Alemany, J. Mater. Chem. 2006, 16, 2729-2735; c) W. Haase, W.; J. Mol. Cat. 1984, 23, 331-340; d) R. Mergehenn, L. Merz, W. Haase, J. Chem. Soc., Dalton Trans. 1980, 1703-1709; e) E. Ruiz, A. Rodriguez-Fortea, P. Alemany, S. Alvarez, Polyhedron 2001, 20, 1323-1327

[7] a) L. Pauling, The Chemical Bond: A Brief Introduction to Modern Structural Chemistry, Cornell University Press: Ithaca, New York, 1967; b) M. Meot-Ner, Chem. Rev. 2005, 105, 213-284; c) S. J. Grabowski. Chem. Rev. 2011, 111, 2597-2625

[8] a) L. M. Salonen, M. Ellermann, F. Diederich, Angew. Chem. Int. Ed. 2011, 50, 4808-4842; b) F. J. M. Hoeben, P. Jonkheijm, E. W. Meijer, A. P. H. J. Schenning. Chem. Rev. 2005, 105, 1491-1546; c) M. Nishio Phys. Chem. Chem. Phys., 2011, 13, 13873-13900; d) S. Mahadevi, G. N. Sastry. Chem. Rev. 2013, 113, 2100-2138

[9] M. Egli, M. Sarkhel, Acc. Chem. Res. 2007, 40, 197-205

[10] A. Bauza, T. J. Mooibroek, A. Frontera, ChemPhysChem 2015, 16, 2496 $-2517$ 
[11] S. K. Singh, A. Das, Phys. Chem. Chem. Phys., 2015, 17, 9596-9612

[12] B. C. Gorske, B. L. Bastian, G. D. Geske and H. E. Blackwell, J. Am Chem. Soc., 2007, 129, 8928-8929

[13] A. Jain, C. S. Purohit, S. Verma, R. Sankararamakrishnan, J. Phys. Chem. B, 2007, 111, 8680-8683

[14] B. W. Gung, Y. Zou, Z. Xu, J. C. Amicangelo, D. G. Irwin, S. Ma, H.-C Zhou, J. Org. Chem. 2008, 73, 689-693

[15] T. J. Mooibroek, P. Gamez, J. Reedijk, CrystEngComm, 2008, 10, 1501

[16] A. W. Addison, T. N. Rao, J. Reedijk, J. van Rijn, G. C. Verschoor, J. Chem. Soc. Dalton Trans. 1984, 1349-1356

[17] J. Novotny, S. Bazzi, R. Marekac, J. Kozelka, Phys. Chem. Chem. Phys., 2016, 18, 19472-19481

[18] G. J. Bartlett, R. W. Newberry, B. VanVeller, R. T. Raines, D. N Woolfson , J. Am. Chem. Soc. 2013, 135, 18682-18688

[19] A. Jain, R.N.V. K. Deepak, R. Sankararamakrishnan, J. Struct. Biol. 2014, 187, 49-57

[20] A. Jain, V. Ramanathan, R. Sankararamakrishnan, Protein Sci., 2009, 18, 595-605

[21] R. W. Newberry, B. VanVeller, I. Guzei, R. T. Raines, J. Am. Chem. Soc. 2013, 135, 7843

[22] G. J. Bartlett, A. Choudhary, R. T. Raines, D. N. Woolfson, Nat. Chem. Biol. 2010, 6, 615-620

[23] a) P. A. M. Dirac, Proc. Roy. Soc. 1929, A123, 714 b) W. Z. Heisenberg, Physik 1926, 38, 411-426; c) W. Z. Heisenberg, Physik 1928, 49, 619636; d) J. H. Van Vleck, In The Theory of Electronic and Magnetic Susceptibilies, Oxford University: London: 1932

[24] (a) V. H. Crawford, H. W. Richardson, J. R. Wasson, D. J. Hodgson, W. E. Hatfield Inorg. Chem. 1976, 15, 2107-2110 (b) L. Merz, W. Haase, J. Chem. Soc. Dalton Trans.1980, 875-879

[25] P. J. Hay, J. C. Thibeault, R. Hoffmann, J. Am. Chem. Soc. 1975, 97, 4884-4899

[26] (a) L. Noodleman, J. Chem. Phys. 1981, 74, 5737-5743; b) L. Noodleman E. R. Davidson, Chem. Phys. 1986, 109, 131-143.

[27] (a) A. D. Pantazis, M. Orio, T. Petrenko, S. Zein, E. Bill, W. Lubitz, J. Messinger, F. Neese, Chem. Eur. J. 2009, 15, 5108-5123; b) D. A Pantazis, M. Orio, T. Petrenko, S. Zein, W. Lubitz, J. Messinger, F. Neese, Phys. Chem. Chem. Phys 2009, 11, 6788-6798; c) C. Baffert, M.
Orio, D. A. Pantazis, C. Duboc, A. G. Blackman, G. Blondin, F. Neese A. Deronzier, M.-N. Collomb, Inorg. Chem., 2009, 48, 10281-10288; d) J.-L. Mathias, H. Arora, R. Lavi, D. Yufit, M. Orio, N. Aliaga, L. Benisvy, Dalton. Trans., 2013, 42, 2358-2361

[28] G. H. Golub, C. Reinsch, Numer. Math. 1970, 14, 403-420

[29] R. Papadakis, E. Rivière, M. Giorgi, H. Jamet, P. Rousselot-Pailley, M. Reglier, A. J. Simaan, T. Tron, T. Inorg. Chem. 2013, 52, 5824-5830.

[30] O. V. Dolomanov, L. J. Bourhis, R. J. Gildea, J. A. K. Howard, H. Puschmann, H. J. Appl. Cryst. 2009, 42, 339-341

[31] (a) L. Palatinus, G. Chapuis, J. Appl. Cryst., 2007, 40, 786-790 ; (b) L. Palatinus, A. van der Lee, J. Appl. Cryst. 2008, 41, 975-984; (c) L. Palatinus, S. J. Prathapa, S. van Smaalen, J. Appl. Cryst. 2012, 45, 575580.

[32] G. M. Sheldrick, Acta Cryst. 2015, C71, 3-8.

[33] F. Neese, Wiley Interdiscip. Rev. Comput. Mol. Sci. 2012, 2, 73-78

[34] (a) J. P. Perdew, Phys. Rev. B 1986, 33, 8822-8824; b) J. P. Perdew, Phys. Rev. B 1986, 34, 7406-7406 (c) A. D. Becke, Phys. Rev. A 1988 , 38, 3098-3100.

[35] A. Schäfer, C. Huber, R. J. Ahlrichs, Chem. Phys. 1994, 100, 5829-5835

[36] F. Neese, J. Comput. Chem. 2003, 24, 1740-1747

[37] F. Weigend, Phys Chem Chem Phys 2006, 8, 1057-1065

[38] A. D. Becke, J. Chem. Phys. 1993, 98, 5648-5652 b) C. T. Lee, W. T. Yang, R. G. Parr, Phys. Rev. B 1988, 37, 785-789.

[39] S. Stoll, A. Schweiger, J. Magn. Reson. 2006, 178, 42-55.

[40] J. W. Hall, W. E. Estes, E. D. Estes, R. P. Scaringe, W. E. Hatfield, Inorg Chem. 1977, 16, 1572-1574

[41] J. D. Chai, M. Head-Gordon, Phys. Chem. Chem. Phys. 2008, 10, 661520.

[42] R. Krishnan, J. S. Binkley, R. Seeger, J. A. Pople, J Chem. Phys. 1980 , $72,650-654$.

[43] a) S. F. Boys, F. Bernardi, Mol. Phys.1970, 19, 553-566; b) S. Simon, M Duran, J. J. Dannenberg, J. Chem. Phys. 1996, 105, 11024-11031.

[44] Reed, A. E.; Curtiss, L. A.; Weinhold, F.; Intermolecular interactions from a natural bond orbital, donor-acceptor viewpoint. Chem. Rev. 1988, 88, 899-926

[45] Chemcraft, http://chemcraftprog.com. 